\title{
Recent advances in research on the aeolian geomorphology of China's Kumtagh Sand Sea
}

\author{
Z. Dong and P. Lv \\ Cold and Arid Regions Environmental and Engineering Research Institute, Chinese Academy of Sciences, No. 320, \\ West Donggang Road, Lanzhou, Gansu Province 730000, China
}

Correspondence to: Z. Dong (zbdong@1zb.ac.cn)

Received: 31 January 2013 - Revised: 27 July 2013 - Accepted: 23 August 2013 - Published: 18 February 2014

\begin{abstract}
The Kumtagh Sand Sea in the hyper-arid region of northwestern China remained largely unexplored until the last decade. It deserves study due to its significance in understanding the evolution of the arid environments in northwestern China, and even central Asia. Aeolian geomorphology in the sand sea has received unprecedented study in the last decade. Encouraging advances have been made in types of aeolian landforms, geological outlines, wind systems, the formation of aeolian landforms, several unique aeolian landforms, aeolian geomorphic regionalization, aeolian geomorphological heritages and tourism development, and aeolian sand hazards and their control. These advances expand our knowledge of aeolian geomorphology.
\end{abstract}

\section{Introduction}

Sand seas and dune fields are widespread throughout northern China, from northeast to northwest (Zhu et al., 1980). Comprehensive expeditions have been conducted in most Chinese sand seas and dune fields since the 1950s. However, the Kumtagh Sand Sea, which is located near the border between China's Gansu Province and the Xinjiang Uygur Autonomous Region, remained largely unexplored because of its severe environments until 2005 (Lu et al., 2012). The Kumtagh Sand Sea had been steeped in mysteries, with the majority of the mysteries centred on the desert's unique aeolian geomorphology. There are some unique types of aeolian landforms in this desert which are not reported in other deserts, such as the raked linear dunes, gravel bodies, and pseudo-feathery dunes; therefore, research on the aeolian geomorphology throughout the sand sea is of great importance.
In 2007, China's Ministry of Science and Technology funded a comprehensive scientific expedition to study the Kumtagh Desert; this expedition comprises nine groups geology, geomorphology, hydrology, meteorology, zoology, botany, pedology, mapping, and integrated landscape planning. The expedition has provided opportunity for investigating aeolian geomorphology throughout the sand sea.

The Kumtagh Sand Sea (Fig. 1) is located at the eastern end of China's Tarim Basin, and straddles Gansu Province and the Xinjiang Uygur Autonomous Region of northwestern China. It covers an area of $22800 \mathrm{~km}^{2}$, is between $89^{\circ} 57.8^{\prime} \mathrm{E}$ and $94^{\circ} 54.1^{\prime} \mathrm{E}$ longitude, and between $39^{\circ} 7.8^{\prime} \mathrm{N}$ and $41^{\circ} 0.1^{\prime} \mathrm{N}$ latitude (Dong et al., 2009). It is bounded by the Lop Nur Depression to the northwest; by an eastern branch of the Tianshan Mountains to the north; and by the Altyn Tagh Mountains, which have been experiencing rapid uplift since the late Pliocene, to the south. In a hyper-arid area of northwestern China, the region's annual precipitation averages less than $30 \mathrm{~mm}$. As more than $95 \%$ of the desert is free of vegetation, the Kumtagh Sand Sea has a diverse range of aeolian landforms.

The geological outlines for the development of aeolian geomorphology of the Kumtagh Sand Sea are investigated in terms of geological structure and stratigraphy. Limited by the available information with respect to the hinterland of Kumtagh Sand Sea, the investigation of geological outlines is mainly based on the research results in the surrounding areas, especially from the Lop Nur area, and the knowledge obtained through field investigation in the hinterland of Kumtagh Sand Sea in recent years (Tang et al., 2010). The basement of the Kumtagh Sand Sea is the eastward extension of the Tarim platform, which experienced complex evolution processes in responses to the evolution of Tarim Basin and 
the uplift of Altyn fault block. Formation of the Kumtagh Sand Sea is closely related to its unique geographical location to the north of Qinghai-Tibetan Plateau, and it is far from any ocean. Its formation is the result of the rapid uplift of the Qinghai-Tibetan Plateau caused by the neotectonic movement and cold dry climate in the Ice Age. Formation of the Kumtagh Sand Sea can be dated back to at least the late Miocene and Pliocene of the late Tertiary period, and it has experienced two primary stages of the late Tertiary and Quaternary (Dong et al., 2011; Lu et al., 2012). The present paper reviews the encouraging advances that have been made in types of aeolian landforms, geological outlines, wind systems, the formation of aeolian landforms, several unique aeolian landforms, aeolian geomorphic regionalization, aeolian geomorphological heritages and tourism development, and aeolian sand hazards and their control. These advances expand our knowledge of aeolian geomorphology.

\section{Types of aeolian landforms}

Identifying the types of aeolian landforms is the basis for further understanding of aeolian geomorphology, and is also a summarization of the research achievements. The Kumtagh Sand Sea has complex types of aeolian landforms although its area is small compared with the other sand seas in the arid regions of China (Dong et al., 2013a). There are also some unique types of aeolian landforms in this sand sea which are not reported in other sand seas and dune fields, such as the raked linear dunes and gravel bodies. The main types of landforms formed by aeolian accumulation in the Kumtagh Sand Sea include aeolian sand ripples, gravel ridges, flat sand land, nebkhas, barchan dunes, barchan chains, barchanoid bridges, reversed dunes, compound transverse mega-dunes, linear dunes, arborization dunes, complex linear dunes and megadunes, reticulate dunes, star (pyramid) dunes and megadunes, compound star dunes, and complex star-shaped dunes. The main types of wind-eroded landforms in the Kumtagh Sand Sea include ventifacts, deflation gobi, yardangs, and gravel bodies. Distribution of the types of aeolian landforms reflects regional differences in the control factor of aeolian landforms. Dunes generally became more complex moving from the north to the south of the study area and from the edges to the inner areas of the sand sea. More than $80 \%$ of the dunes in the Kumtagh Sand Sea were less than $100 \mathrm{~m}$ tall, but with maximum heights exceeding $300 \mathrm{~m}$. Dune height increased from the north to the south, with the tallest dunes occurring near the southern mountains.

The formation process of aeolian landforms is one of the primary aspects in the study of aeolian geomorphology. The types of aeolian landforms in the Kumtagh Desert are complex, and hence the formation process and influence factors must also be complex. Our present knowledge of aeolian geomorphology is still relatively poor. Therefore, some main types of aeolian landforms in the Kumtagh Sand Sea are se- lected as research objects. Formation of aeolian landforms in the Kumtagh Sand Sea shares some common processes with other deserts around the world, but also has several unique processes. Sand availability is the primary control factor to form macro-aeolian patterns (Qu et al., 2005; Dong et al., 2011). Attempts are being made to make progress in studying aeolian geomorphology in the Kumtagh Sand Sea on the basis of previous research in aeolian geomorphology. The formation processes of several primary dune types are investigated in detail. The following are studied: air flow characteristics over transverse dunes and nebkhas, development models of raked linear dunes, star dunes, and formation processes and control factors of yardangs, ventifacts, and desert pavement (Dong et al., 2011, 2012b, 2013b). It is found that the wind directions in this desert are very complicated and very variable. Blown sand activity in the desert is very strong, as most regions of the desert have high wind energy and a sand drift potential of 200-400 VU (vector unit).

Researchers from China have begun to show unprecedented interest in feathery dunes as the study of the Kumtagh Sand Sea proceeds. However, more and more arguments centring on feather dunes have arised (Dong et al., 2008; Qu et al., 2011). After reviewing dune classifications proposed by several authors, it is recognized that feathery dunes are a variety of compound linear ridge in which the main ridge acts as a "shaft" and subsidiary linear dunes diverging from the main ridge act as "feathers". Comparing morphology of the feather dunes reported in other deserts around the world and those found in the Kumtagh Sand Sea reveals that the so-called feather dunes in the Kumtagh Sand Sea are in fact not real feather dunes but instead typical seif dunes. The "feathers" erroneously assumed on remote sensing images are patterns reflecting albedo contrast of the ground surface sediments. They have no corresponding relationship to the relief on the inter-seif dune corridors. Feather dunes are developed in a complex wind regime with insufficient sand supply. Consequently, we proposed that the misconception of feather dunes held by Chinese researchers be corrected (Xia, 1987; Dong, 2009; Qu et al., 2009).

The special geographical environment in the Kumtagh Sand Sea causes the aeolian landforms to have several unique characteristics, which are indicated in such aspects as morphology (types of aeolian landforms) and spatial patterns. The linear dunes in the north of the Kumtagh Sand Sea draw more attention in aeolian geomorphology, and there is much debate about them. The linear dunes given above are identified as raked linear dunes based on morphological characteristics of the dunes observed through field investigation and satellite images (Dong et al., 2012a). Formation of the Kumtagh Sand Sea can be dated back to at least the late Miocene and Pliocene of the late Tertiary period, and it has experienced two primary stages of the late Tertiary and Quaternary (Wu and Guo, 2012). Gravel bodies under the combined effects of diluvial and aeolian erosion are found in the north of the Kumtagh Sand Sea (Dong et al., 2010b). The special 


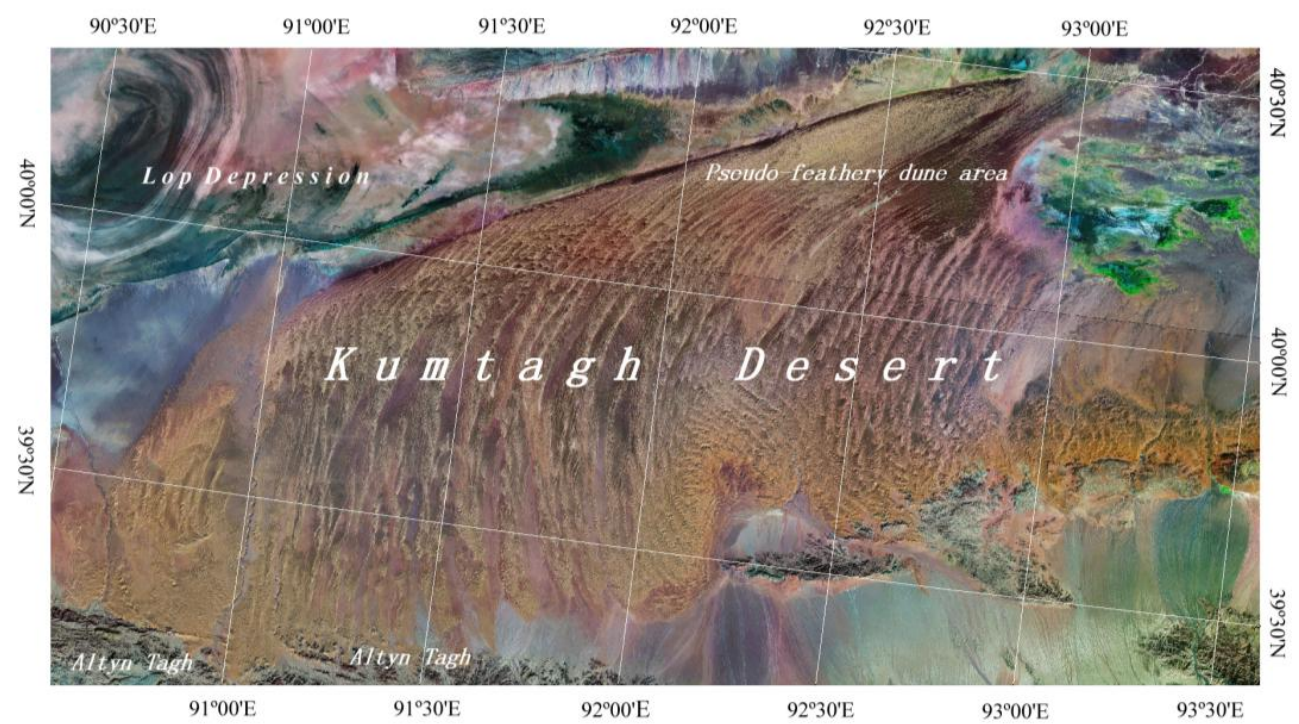

Fig. 1. Map of the Kumtagh Sand Sea.

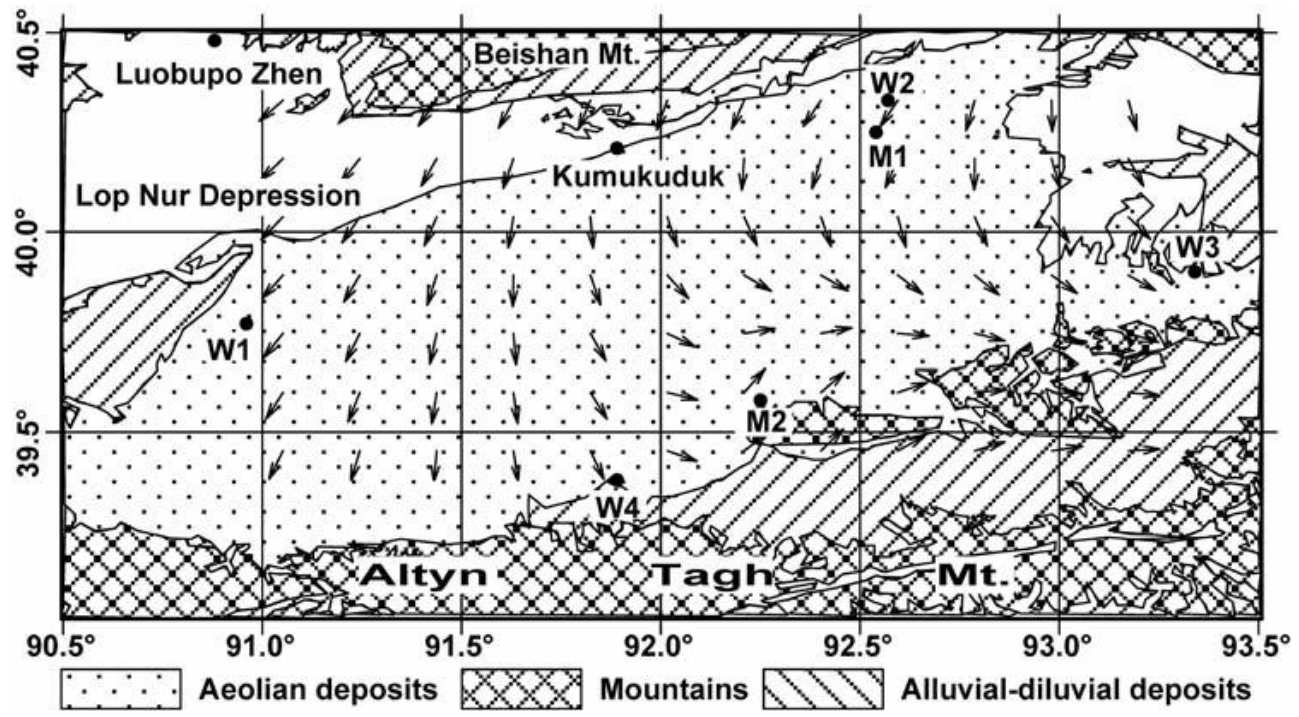

Fig. 2. Wind regimes in the Kumtagh Desert.

geomorphic patterns of the region covered with the linear dunes in the north of the desert are analysed with the method of geomorphological pattern analysis (Dong et al., 2010b); this method consists in analysing the relationship between cumulative frequency plots of dune spacing and crest length to create statistical populations, and has been introduced to dune geomorphology in recent years (Ewing et al., 2006).

\section{Controlling factors on aeolian sediments}

Sediment constitutes the material base for the development of aeolian geomorphology, and hence needs to be clearly expounded in the study of regional aeolian geomorphology.
Sediment characteristics of the Kumtagh Sand Sea are investigated in terms of the grain size distribution and mineralogical and geochemical compositions (Wei et al., 2007; Tang et al., 2008; He et al., 2009; Xu et al., 2010). Mean grain size of surface sediments in the Kumtagh Sand Sea varies between $\sim 2.02 \varphi$ and $\sim 3.06 \varphi(\sim 0.12$ to $\sim 0.25 \mathrm{~mm})$, meaning medium to fine sands (Fig. 2). They are well to moderately well sorted, with a phi sorting index of $\sim 0.35$ to $\sim 0.82$. As it is influenced by the provenance and chemical weathering degree, the mineral composition of sediments in the Kumtagh Sand Sea is complex. The content of unstable minerals such as light minerals and various rock debris is relatively high, but heavy mineral composition is relatively low. The 


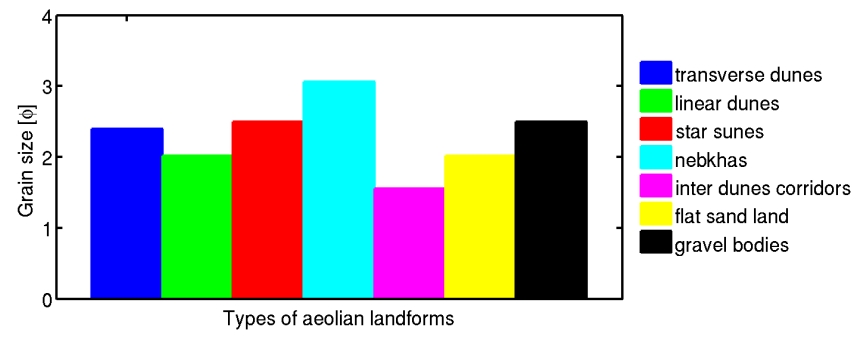

Fig. 3. Distribution of sand grains in the Kumtagh Desert.

composition of light minerals in the sediments of the Kumtagh Sand Sea is considerably different from that of other deserts, with lower quartz content but higher feldspar content. Sediment supply for the Kumtagh Sand Sea is mainly from weathering and erosion of the Altyn Mountains to the south and low mountains and hills to the east. Regional differences in sediments are further promoted by the prevailing wind and the local air flow circulation caused by the mountains, which leads to the differential sorting and transport of sediments.

Wind provides the power for the formation and development of aeolian geomorphology. The mean seasonal pressure at sea level and the seasonal mean air current of the Kumtagh Sand Sea is investigated based on previous research results (Zhao et al., 2010). The surface wind regime is analysed and discussed according to the wind data acquired from six weather- or wind towers set up in 2007 (Zeng et al., 2008). Sand drift potential is analysed in detail (Zhang et al., 2010); most regions of the desert belong to areas of high wind energy and have a sand drift potential of 200-400 VU. The wind power system responsible for the formation and development of aeolian geomorphology in the Kumtagh Sand Sea is controlled by both the planetary wind system and local air circulation. Wind energy is within the range of intermediate to high wind energy environments, higher than other Chinese sand seas. There are regional differences in both wind direction and strength, corresponding well to the regional variation in dune types. The wind system (Fig. 3) in the Kumtagh Sand Sea varies spatially, which reflects the effect of Qinghai-Tibetan Plateau to some extent, implying the influence of the Qinghai-Tibetan Plateau on the formation and evolution of aeolian geomorphology in the Kumtagh Desert (Dong et al., 2012a; Lv and Dong, 2012).

\section{The geomorphic mapping and regionalization}

The general ideas and technologies employed are presented for compiling the geomorphic map of the Kumtagh Sand Sea (Dong et al., 2010c). The scale of the map is determined as 1:350000, considering the thematic details to be shown and the required specification of printing paper. Land maps of 1:250000 scale prepared in the 1970s are selected as the geography base maps, supplemented by the 1:100000 land maps for details of some elements. Thematic contents are based on TM data of 2000 to 2007, supplemented by the high-resolution images provided by Google Earth in some areas. The thematic contents included geomorphic types, height, and activities. The geomorphic types are classified as aeolian landforms, fluvial landforms, dry denuded landforms, glacial and periglacial landforms, and other landforms. Aeolian landforms are the key elements to be manifested in the thematic map. Aeolian landforms are classified into 13 types represented by symbols, with their relative height represented by colours and activities represented by arrows. Primary dunes generally higher than $10 \mathrm{~m}$ are sited, and those less than $10 \mathrm{~m}$ in height are non-sited to show the distribution and patterns of aeolian landforms and consider the limitation of the mapping scale. Alluvial fans and dry streams are also the key factors to be presented because the Kumtagh Sand Sea was developed on the inclined alluvial plains to the north of the Altyn Mountains. Computer mapping and digitization technology are applied to their best. All the information that could be digitized is digitized. A geomorphic map of the Kumtagh Desert would provide rich information for studying the desert (Dong and Qu, 2009).

As a preliminary summary of aeolian geomorphic research, attempts are made to study the aeolian geomorphic regionalization in the Kumtagh Sand Sea. Aeolian geomorphological regionalization is a preliminary summarization of the research in aeolian geomorphology (Dong et al., 2011b). With the theoretical guidance of regional differentiation regularity in geomorphology, the principles followed include genetic similarity, multi-order division, and a combination of comprehensive analysis and dominant factors. A two-order regionalization system is presented by means of top-down division order and selecting leading factors. The regions of the first order (geomorphological regions) are divided in terms of causes of the underlying landforms, and the regions of the second order (geomorphological sub-regions) are divided in terms of the aeolian morphology of landforms. The present scheme divides the aeolian geomorphology of the Kumtagh Sand Sea into 7 regions and 23 sub-regions. The characteristics of each region and sub-regions are described briefly.

\section{Conclusions}

Aeolian geomorphological heritage and tourism development are the research aspects of applied aeolian geomorphology. However, the study of geomorphological heritage is still in its beginning stage. Successful practices of tourism development of the geomorphological heritage have been carried out in such areas in the Kumtagh Sand Sea as the Mingshashan, Crescent Lake, and Yardang National Geological Park. A brief evaluation on the value of the aeolian geomorphology in the Kumtagh Sand Sea as a world nature heritage is provided in terms of aesthetic, social economic, 
cultural, and scientific value (Wu et al., 2012a). The significance and the methods of tourism development, as well as possible problems facing it, are suggested (Wu et al., 2012b).

The control of blown sand hazards is an important research aspect of regional aeolian geomorphology. Aeolian sand hazards threaten the survival of human beings. The control practices of aeolian sand hazards in the Kumtagh Sand Sea are mainly conducted in the surrounding areas, especially in Dunhuang area. Sand drift in desert pavement has some unique characteristics compared with that in shifting dune fields, and hence presents special hazards. The flux profile and speed of an aeolian sand cloud in a wind tunnel are simulated in a wind tunnel. Aeolian sand hazards to Mogao Grottoes in Dunhuang have received wide attention from the Chinese Government and international communities $(\mathrm{Qu}$ et al., 1997), and thus the successful practices for controlling the aeolian sand hazards to Mogao Grottoes in Dunhuang have being introduced to provide experience that can be used in areas suffering similar aeolian sand hazards (Zhang et al., 2000).

Acknowledgements. We gratefully acknowledge funding from the China National Science and Technology Basic Research Programme (2012FY111700) and the National Science Foundation of China (41130533).

Edited by: F. Métivier

Reviewed by: two anonymous referees

\section{References}

Dong, Z. B.: The identification of feathery dunes, Review of Science and Technology, 27, 69-75, 2009. (in Chinese with English abstract)

Dong, Z. B., Qu, J. J., Wang, X. M., Qian, G. Q., Luo, W. Y., and Wei, Z. H.: Pseudo-feathery dunes in the Kumtagh Desert, Geomorphology, 100, 328-334, 2008.

Dong, Z. B., Qian, G. Q., Yan, P., and Su, Z. Z.: Gravel bodies in the Kumtagh Desert and their geomorphological implications, Environ. Earth Sci., 59, 1771-1779, 2010a.

Dong, Z. B., Wei, Z. H., Qian, G. Q., Zhang, Z. C., Luo, W. Y., and Hu, G. Y.: "Raked" linear dunes in the Kumtagh Desert, China, Geomorphology, 123, 122-128, 2010 b.

Dong, Z. B., Qu, J. J., Lu, J. H., Qian, G. Q., Wang, X. M., and Luo, W. Y.: Compilation of geomorphic map of the Kumtagh Desert, J. Desert Res., 30, 483-491, 2010c. (in Chinese with English abstract)

Dong, Z. B., Su, Z. Z., Qian, G. Q., Luo, W. Y., Zhang, Z. C., and Wu, J. F.: Aeolian Geomorphology of the Kumtagh Desert, Science Press, Beijing, 484 pp. (in Chinese with English Summary), Science Press, Beijing, 2011a.

Dong, Z. B., Qu, J. J., Qian, G. Q., and Zhang, Z. C.: Aeolian geomorphological regionalization of the Kumtagh Desert, J. Desert Res., 31, 805-814, 2011b. (in Chinese with English abstract)

Dong, Z. B., Zhang, Z. C., Lv, P., Qian, G. Q., and Luo, W. Y.: Analysis of the wind regime in context of dune geomorphology for the Kumtagh Desert, Northwest China. Zeitschrift für Geomorphologie, 56, 459-475, doi:10.1127/0372-8854/2012/0085, 2012a.

Dong, Z. B., Lv, P., Lu, J. F., Qian, G. Q., Zhang, Z. C., and Luo, W. Y.: Geomorphology and origin of Yardangs in the Kumtagh Desert, Northwest China. Geomorphology, 139-140, 145-154, doi:10.1016/j.geomorph.2011.10.012, 2012b.

Dong, Z. B., Qian, G., Luo, W., and Zhang, Z.: Dune types and their distribution in the Kumtagh Sand Sea, northwestern China, Zeitschrift für Geomorphologie, 57, 207-224, doi:10.1127/03728854/2012/0099, 2013a.

Dong, Z. B., Zhang, Z. C., Qian, G. Q., Luo, W. Y., and Lv, P.: Geomorphology of star dunes in the southern Kumtagh Desert, China: Control factors and formation, Environ. Earth Sci., 69, 267-277, doi:10.1007/s12665-012-1954-y, 2013b.

He, Q., Yang, X. H., Huo, W., Wang, S. G., Shang, K. Z., and Liu, H. Y.: Characteristics of sand granularity from Kumtag Desert and its environmental significance, J. Desert Res., 19, 18-22, 2009. (in Chinese with English abstract)

Ewing, R. C., Kocurek, G., and Lake, L. W.: Pattern analysis of dune-field parameters, Earth Surf. Proc. Land., 31, 1176-1191, 2006.

Lu, Q., Wu, B., Dong, Z. B., Lu, H. Y., Xiao, H. L., and Wang, J. H.: A Study of the Kumtag Desert, 456 pp., (in Chinese with English Summary), Science Press, Beijing, 2012.

Lv, P. and Dong, Z. B.: Wind field and temperature field in the nearsurface layer in Kumtagh Desert, J. Desert Res., 32, 442-446, 2012. (in Chinese with English abstract)

Qu, J. J., Dong, G., R., Wen, Z. X., and Zhang, W. M.: Sand drift encroachment in the Dunhuang Mogao Grottoes District and its control, Sci. in China (Series D: Earth Sci.), 40, 197-206, 1997.

Qu, J., Zuo, G., Zhang, K., and Zu, R.: Relationship between the formation and evolution of the Kumtagh Desert and the regional neotectonic movement, Arid Land Geogr., 28, 424-428, 2005. (in Chinese with English abstract)

Qu, J., Liao, K., Zu, R., Xia, X., Jing, Z., Dong, Z., Zhang, K., Yang, G., Wang, X., and Dong, G.: Study on the formation of feather-shaped sand ridge in Kumtagh Desert, J. Desert Res., 27, 349-353, 2007. (in Chinese with English abstract)

Qu, J. J. Liao, K. T., Dong, G. R., Niu, Q. H., Jing, Z. F., and Han, Q. J.: Feathered sand ridges in the Kumtagh Desert and their position in the classification system, Sci. China Earth Sci., 54, 12151225, 2011.

Tang, J. N., Wang, J. H., Su, Z. Z., Ding, F., Liao, K. T., Liu, H. J., Zhang, G. Z., Zhang, Q. Z., Zhang, J. C., and Youhao E.: Grain size parameters and their distribution on feather-like dune of Kumtag Desert, Arid Land Geogr., 31, 918-925, 2008. (in Chinese with English abstract)

Tang, J. N., Su, Z. Z., Ding, F., Liao, K. T., Youhao, E., Zhai, X. W., Wang, J. H., Yi, Z. Y., Liu, H. J., and Zhang, J. C.: Formative age and evolution of Kumtagh Desert, Arid Land Geogr., 33, 325333, 2010. (in Chinese with English abstract)

Wei, H. D., Xu, X. Y., Wang, J. H., Tang, J. N., Liu, H. J., Ding, F., Liao, K. T., Zhao, M., Zhang, J. C., Zhang, Y. C., and Zhang, L. W.: Analysis of grain size of different sand dunes types in Kumtag Desert, J. Soil Water Conserv., 21, 6-9, 2007. (in Chinese with English abstract)

Wu, J. F. and Guo, F.: Geomorphological patterns in a linear dune field and ages of the linear dunes in the northern Kumtagh 
Desert,northwest China, Environ. Erath Sci., 66, 2449-2457, 2012.

Wu, J. F., Guo, F., Wang, X., and Li, L.: Aesthetic value of aeolian geomorphosites in the Kumtagh Desert, China, J. Desert Res., 32, 1451-1456, 2012a. (in Chinese with English abstract)

Wu, J. F., Guo, F., Wang, X., and Li, L.: Tourism development of aeolian geomorphosites in the Kumtagh Desert, China, J. Desert Res., 32, 1163-1168, 2012b. (in Chinese with English abstract)

Xia, X.: Some characteristics of the Kumtagh Desert, edited by: Xia, X., Scientific Expedition in Lop Nor. Science Press, Beijing, 1987. (in Chinese)

Zeng, X. Q., Wang, S. G., Shang, K. Z., and Zeng, S. L.: A Study of wind system in Kumtag Desert, J. Desert Res., 29, 391-396, 2009. (in Chinese with English abstract)

Zhang, W., Wang, T., Xue, X., Wang, W., Guo, Y., and Liu, J.: The discuss of comprehensively preventing blown-sand system in Mogao Grottoes, Dunhuang, J. Desert Res., 20, 409-414, 2000. (in Chinese with English abstract)
Zhang, Z. C., Dong, Z. B., Zhao, A. G., and Qian, G. Q.: Characteristics of blown sand activity in the Kumtagh Desert, Arid Land Geogr., 33, 939-946, 2010. (in Chinese with English abstract)

Zheng, B. X., Qu, J. J., Shen, Y. P., Niu, Q. H., Yu, Q. H., and Zhao, A. G.: Feathery faults formation in Kumtagh Desert: Bayiquan Tectonic Movement and its relationship among QinghaiTibet Plateau uplift and climate change, J. Glaciol. Geocryol., 34, 591-596, 2012. (in Chinese with English abstract)

Zhao, Y., He, Q., and Huo, W.: Characteristics of climate change around Kumtage Desert, J. Arid Meteorol., 28, 291-296, 2010. (in Chinese with English abstract)

Zhu, Z. D., Wu, Z., Liu, S., and Di, X. M.: Deserts in China, Science Press, Beijing, 107 pp., 1980. (in Chinese)

Xu, Z. W., Lu, H. Y., Zhao, C. F., Wang, X. Y., Su, Z, Z., Wang, Z. T., Liu, H. Y., Wang, L. X., and Lu, Q.: Composition, origin and weathering process of surface sediment in Kumtagh Desert, Northwest China, Acta Geogr., 65, 53-64, 2010. (in Chinese with English abstract) 